\title{
Reversible Nanoporous Sensors of Carbon Monoxide in Atmosphere
}

\author{
Alexander Novikov \\ Saint Petersburg National Research University of Information Technologies, Mechanics and Optics, \\ Department of Physical Engineering, Kronwerksky, Saint Petersburg, Russia. \\ afnovikov@mail.ru
}

\begin{abstract}
Optical chemical compositions being sensitive to carbon monoxide in atmosphere were investigated and tested. The gas sensitive Palladium (II) complexes were immobilized within nano-scale throughout porous glass substrates. Fabricated specimens have demonstrated reversible color changes while interaction with gaseous carbon monoxide in atmosphere.
\end{abstract}

Keywords: Optical chemical sensors, Carbon monoxide detection, Nanoporous glass composition materials, Palladium complexes.

\section{Introduction}

Atmosphere content analysis often requires the portable sensors of carbon monoxide (CO). The most popular $\mathrm{CO}$ detectors are the single-shot Dräger indicator tubes [1] using particularly the iodine chemical reduction by $\mathrm{CO}$. Also a row of various sensor devices intended for $\mathrm{CO}$ detection are now at disposal. They are based on different principles such as electrochemical, catalytic, optical and infrared absorption, etc. sensors [2-5]. In general, those sensors demonstrate enough good performances, however, accompanied with certain disadvantages mainly connected with so-called cross-sensitivity. As a rule, the designers have to solve a problem of distinguishing namely $\mathrm{CO}$ component in presence of other reducing atmosphere components. So an attempt to find out new solution of the said problem seems to be just relevant.

Specific chemical reaction of the CO gas with Palladium (II) salt is well-known [6]. During a solution barbotage with gas, the metallic Palladium rapidly precipitates, so that originally brown solution instantly and irreversibly gets colorless:

$$
\begin{gathered}
\mathrm{PdCl}_{2}+\mathrm{H}_{2} \mathrm{O}+\mathrm{CO} \rightarrow \mathrm{Pd} \downarrow+\mathrm{CO}_{2}+\mathrm{H}_{2}, \\
\text { or } \\
{\left[\mathrm{PdCl}_{4}\right]^{2-}+\mathrm{H}_{2} \mathrm{O}+\mathrm{CO} \rightarrow \mathrm{Pd} \downarrow+\mathrm{CO}_{2}+2 \mathrm{H}^{+}+4 \mathrm{Cl}^{-} .}
\end{gathered}
$$

The latter reaction supposedly proceeds in two steps as follows [7]:

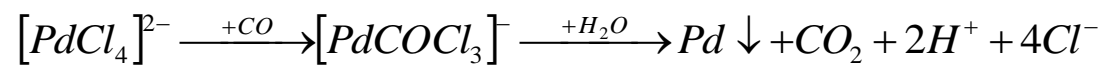

Principally, the process can't be run gradually, and a required sensing instrument calibration is impossible. However, the time spreading the process may be provided with use of the more complicated solution composition and procedure as shown in [8]. 
But probably the most prospective way in this sense were to abandon the liquid medium at all and so to immobilize certain palladium complexes on a dry dielectric surface.

This seems to be available with use of the certain palladium complexes being adsorbed on the properly pretreated dielectric surface. As an appropriate substrate in similar applications proved to be a matrix made of the nano-scale porous silicate glass. Presently, the structure and properties of nanoporous glasses as they are have been thoroughly studied by many researchers [9-11].

Methods for precipitation of various dopants within nano-scale porous silicate glass have been invented enough long time ago [12]. However, only during recent decades the intensive studies have been carried out having as an object the organic and inorganic molecular clusters down to single molecules being immobilized on the highly developed surface of the nanoporous glass $[9,10,13]$.

A large specific area of nanoporous glasses (up to $100 \mathrm{~m} 2 / \mathrm{cm} 3$ and higher) provides a uniform spatial distribution of particles within porous sample, so that the particles immobilized on the matrix surface may be properly investigated. Amongst others the optical properties are of special interest because the optical sensors of the gas/atmosphere components have demonstrated its good performances and are widely used in the chemical analytical practice [4,5]. Particularly, spectral methods have proved its applicability and effectiveness here. In principal, these methods allow to detect optical signals produced even by single molecules [15].

First of all, the nanoporous glass is not anyhow a passive substrate for the adsorbed substance - on the contrary, the inherent matrix properties exert a critical impact on the composition properties on the whole. In contrast to the molecules being dissolved in the liquid solution, the same molecules being immobilized within highly developed nanoporous matrix behave substantially in different way. This situation causes certain peculiarities in spectral characteristics of immobilized molecules that are not event in case of molecules in solutions. Investigations of this matter might open good application prospects of the obtained results for developments of the optical chemical sensors including $\mathrm{CO}$ sensors.

As a complexing agent, the same $\mathrm{Pd} 2+$ ion was selected with taking into consideration the following ideas. This ion is able to form the number of intermediate carbonyl-halogenide coordination compounds and therefore to produce a gradual color transition of the composition samples. The $\mathrm{Pd} 2+$ ion has an electronic configuration $\mathrm{d} 8$, thus it might form the donor-acceptor bound with $\mathrm{CO}$ electron pairs.

\section{Experimental}

\subsection{Sample preparation}

Nanoporous samples were produced using the stepwise thermal and chemical treatment following a well-known Vycor process $[9,10]$. Original solid glass was a liquated sodium-borate-silicate glass (sodium oxide -6.8 mass. $\%$, boron oxide $-26.7 \%$, silicon oxide $-66.0 \%$, the rest - other components) with phase separation. After having been treated in an aqueous solution of hydrochloric acid $\mathrm{HCl}(3 \mathrm{~N})$, a sodium-borate phase was leached out, thereafter the samples were annealed in air at $+550{ }^{\circ} \mathrm{C}$. Such procedures resulted in a through-out open porous structure within a substantially silica framework.

Next a procedure of the porous matrix impregnation followed in solution of the selected palladium salt. The procedure lasted until sorption equilibrium having been achieved. The salt molecules were forced to penetrate into nanoporous glass from the acetone, ethanol and dimethyl sulfoxide 
solutions. The samples were then extracted from the initial solutions and dried in air at $+50{ }^{\circ} \mathrm{C}$ in order to evaporate the solvent out of the matrix.

By means of described treatment the salt molecules have been fixed onto pores surface.

The samples were the plates of various thicknesses within $0.2-1.0 \mathrm{~mm}$.

\subsection{Spectral measurements}

The absorption spectra of the samples and impregnating solutions were run on the spectrophotometers U-3200 (Hitachi, Japan), Lambda19 (Perkin-Elmer, USA) and CФ-26 (LOMO, Russia) within the wave range $300-800 \mathrm{~nm}$.

During measurements, the samples were put into optically transparent cell being blown-through with $\mathrm{CO}$ containing air. Before taking readings, the samples were kept in the analysed gas mixture for sufficient time (10 min or longer). The reference spectral characteristics relate to the samples having been kept in normal laboratory atmosphere (relative humidity of $50 \%$ at $20^{\circ} \mathrm{C}$ ).

\section{Results and discussion}

\subsection{Studies of original nanoporous matrix}

Small-angle X-ray techniques as well as a routine processing the adsorption isotherms in the area of capillary condensation have revealed the pore size distribution in vicinity of $8-9 \mathrm{~nm}$ [14], the porosity being of $28 \%$ of the total sample volume. Specific area, calculated from a specific bending point on the isotherm curve, turned out to be about $105 \mathrm{~m}^{2} / \mathrm{cm}^{3}$.

The studied porous glass exhibits an absorption isotherm of IV type (A-subtype) according to the Gregg's classification [16]. This fact witnesses the long-capillary pore structure. The resulted porous structure was permeable for gases and liquids, and the samples were practically transparent in the visible wave range.

\subsection{Spectral studies of immobilized Palladium(II) chloride}

In Figure1 (curve 1) an absorption spectrum of the initial impregnating medium is displayed. This medium being the acidulous water solution of $\mathrm{PdCl}_{2}$. The spectrum shape is typical for the planar tetra-coordinated complexes of the Platinum row metals. Specifically, an absorption band at $350 \mathrm{~nm}$ may be assigned to transition connected with a charge transfer from ligand to metal in the dimer particles $\left[\mathrm{Pd}_{2} \mathrm{Cl}_{6}\right]^{2-}[17,18]$. A broader band at $456 \mathrm{~nm}$ most probably belongs to the $d-d$ transitions within Palladium ions. The curve 2 in Figure1 presents the spectrum of nanoporous sample containing the immobilized Palladium (II) chloride complexes. Lowering of the adsorption maxima may be caused by the restriction of the vibrational degree of freedom of particles immobilized on the pores surface. 


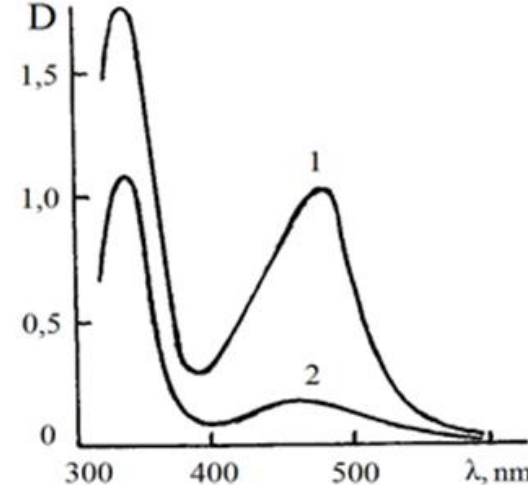

Figure 1: Absorption Spectra of the $\mathrm{PdCl}_{2}$ acidulous water solution (1 mass \%)-(1); and nanoprous sample processed in this solution- (2)

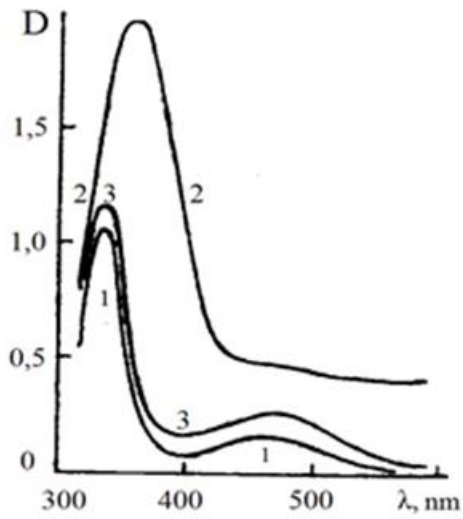

Figure 2: Absorption Spectra of the processed nanporous sample: in the initial atmosphere- (1); in the $\mathrm{CO}$ atmosphere (70 vol \%)-(2); in the initial atmosphere again- (3).

In Figure2. a spectral response of the nanoporous sample on the carbon monoxide in atmosphere is presented. As one can see, the response was significant but rather slowed down. Air blowing the optical cell with clean air returned the spectrum to the initial shape, however, the sample spectrum recovered not entirely. Nevertheless the very fact of spectral recovery witnesses that metallic palladium reduction does not take place in this case. Most probably the intermediate complexes of the Palladium carbonyl-halogenides are formed on the dry pores surface. The most stable among them are the monomeric complexes $\left[\mathrm{PdCOCl}_{3}\right]^{-}$, or dimer ones $\left[\mathrm{Pd}_{2}(\mathrm{CO})_{2} \mathrm{Cl}_{6}\right]^{2-}$. In general, the process may be written in such a way:

$$
\begin{aligned}
& {\left[\mathrm{PdCl}_{4}\right]^{2-}{ }_{\text {surf. }}{ }^{+} \mathrm{CO} \rightarrow\left[\mathrm{Pd}(\mathrm{CO}) \mathrm{Cl}_{4}\right]^{2-}{ }_{-\mathrm{Cl}^{-}} \rightarrow} \\
& \rightarrow\left[\mathrm{Pd}(\mathrm{CO}) \mathrm{Cl}_{3}\right]^{-}{ }_{-\mathrm{Cl}^{-}} \rightarrow\left[\mathrm{Pd}(\mathrm{CO}) \mathrm{Cl}_{2}\right] .
\end{aligned}
$$

In essence, this reaction proceeds as an associative mechanism of the $S_{N} 2$ lim type with formation of the rectangular pyramid. For avoiding the irreversible signal component, the glass surface should be chlorinated, however, it helped weakly.

In addition, the $\mathrm{CO}$ molecules could also take a bridge position between the adsorbed monomeric complexes. Some of them could remain fixed in this position on the pore surface providing an observed irreversible component of the spectral response. If so, cycling the $\mathrm{CO}$ attacks on the sample might improve the situation.

\subsection{Spectral studies of immobilized Palladium (II) complexes}

The encouraging results have been obtained with use of the more complicated compound such as Pd2-di- $\mu$-dibromo-bis-(di-n-propyl sulfoxide):

$$
\begin{array}{r}
\mathrm{O}=\underset{\mid}{\mathrm{S}} \rightarrow \underset{\mid}{\mathrm{Pd}} \leftarrow \underset{\mid}{\mathrm{Cr}_{3} \mathrm{H}_{7}} \underset{\mid}{\mathrm{C}_{3} \mathrm{H}_{7}} \\
\mathrm{C}_{3} \mathrm{H}_{7} \mathrm{Br} \rightarrow \underset{\mid}{\mathrm{Pd}} \leftarrow \underset{\mid}{\mathrm{Sr}} \mathrm{C}_{3} \mathrm{H}_{7}
\end{array}
$$

Noteworthy is the complex being initially a bridged dimer [19]. 
Spectra of the complex solutions in different solvents have been run. As an optimum solvent, dimethyl sulfoxide was selected because it's being homologous to dipropyl sulsoxide. Spectrum of this solution is displayed in Figure3 (curve 1). Compared with Palladium (II) chloride, spectrum in Figure3 demonstrates the same two bands revealing presence of the dimeric molecules and electron transitions within Palladium(II) ions. However, the latter band is less expressed and being shifted to the shorter wave lengths.

These dimeric complexes are known to dissociate down to monomeric ones under action of the carbon monoxide molecules (see the reaction below) [20]. In Figure3 (curve 2) a spectrum of the bubbled solution is presented, one can see the lowering the dimer absorption band. Indeed, after barbotage procedure the solution gets clearer, and the precipitation process takes place. Surely, the sediment was thoroughly filtered off.

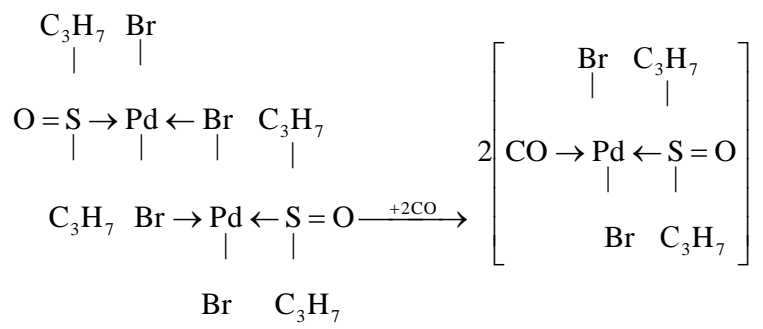

Taking into consideration such behavior of the system, we have used procedure of the porous samples impregnation in solutions of both non-bubbled and previously bubbled by the gaseous carbon monoxide. In Figure 4 the corresponding spectra are presented.

The nano-porous samples impregnated with that residual solution and then properly dried turned out to be potentially more suitable as the sensitive elements of the CO detectors. The more as the spectral response under the same conditions was almost entirely reversible. The surface reaction in this case does not proceed due to irreversible reduction of the Palladium ion by the CO molecules. The reaction mechanism includes only a bridging process accompanied by configuration changes in coordinative sphere of immobilized ion. Therefore optical response is exceptionally produced by CO molecules, and it provides very high selectivity of the sensor signal.

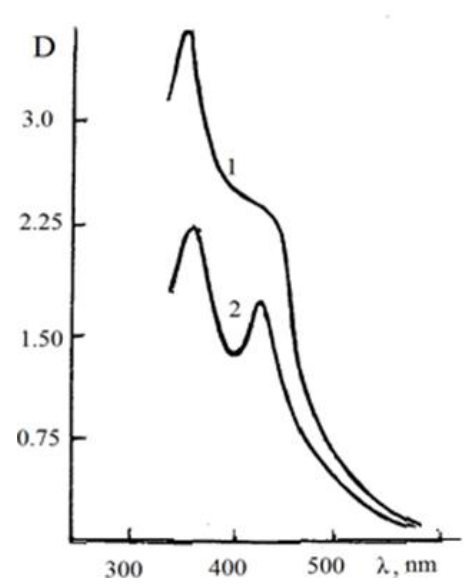

Figure 3: Absorption Spectra of the dimethyl sulfoxide solution of the Palladium (II) complex: 1-before barbotage; 2-after barbotage.

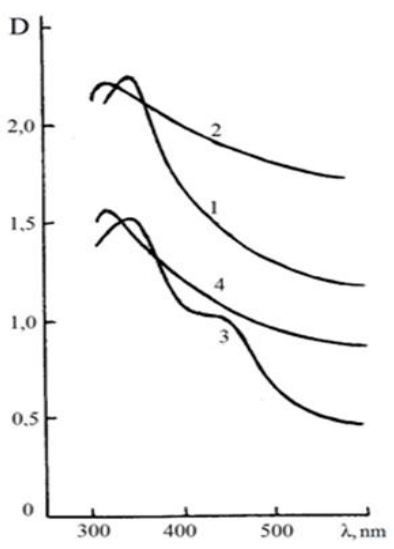

Figure 4: Absorption Spectra of the nano-porous samples processed in the dimethyl sulfoxide solution of the Palladium (II) complex: 1-sample from non-bubbled initial solution, normal atmosphere; 2-the same in the $70 \% \mathrm{CO}$ atmosphere; 3 and 4 - the same from bibbled solution, respectively. 
So, one can see that the $\mathrm{CO}$ concentration change by $70 \%$ produces the optical density change by about 0.5 (i.e. by $50 \%$ ). Using the modern precise optoelectronic facilities, a high sensitivity to the $\mathrm{CO}$ appearance in atmosphere may be provided as well. Much better results might be achieved with use of a double wave lengths detection scheme (at 400 and $600 \mathrm{~nm}$ ).

However, a time constant of the prototype sensors is rather high - about $5 \mathrm{~min}$.

\section{REFERENCES}

[1] Dräger Werk AG. Product Catalog. Detector Tube Handbook, 2010.

[2] Thompson C. V., Goedert M. G. Field-Portable Instrumentation for Gas and Vapor Samples. In: Encyclopedia of Analytical Chemistry / Ed. by Meyers R. A., John Wiley and Sons, Inc. Vol. 14, Field-portable Instrumentation, 2009.

[3] Opekar F., Štulík K. Electrochemical Gas Sensors. Ibid. Vol. 9, Electroanalytical Methods, 2009.

[4] Lucena R. Infrared Sensors. Ibid. Vol. 20, Infrared Spectroscopy, 2010.

[5] Saltzman R. S. Ultraviolet/Visible Spectroscopy in Process Analyses. Ibid. Vol. 33, Process Instrumental Methods, 2011.

[6] Holleman A. F., Wiberg E. Inorganic Chemistry. Academic Press. San Diego, 2001.

[7] Livingstone S.A. The Chemistry of Ruthenium, Rhodium, Palladium, Osmium, Iridium and Platinum, Oxford: Pergamon Press. 1973.

[8] T. H. Allen, W. S. Root. Colorimetric Determination of Carbon Monoxide in Air by an improved Palladium Chloride Method. // Journ. Biol. Chem. 1955. V. 216, No.1, pp. 309317.

[9] Yanowski F., Heyer W. Poröse Gläser. Herstellung, Eigenschaften, Anwendung. I Auflage. Leipzig: VEB Deutscher Verlag für Grundstoffindustrie. 1981. 276 S.

[10] Enke D., Janowski F., Schwieger W. Porous glasses in the 21st century - a short review // Microporous and Mesoporous Materials. 2003. V. 60. N 1-3. P. 19-30.

[11] Macedo P. B., Litovits T. A. Method of precipitation of dopants in a porous silicate glass. Patent USA No. 4110096, publ. 29.08.78.

[12] Novikov A.F. Nanoporous silica glass sensibilisation in respect to the gas components detection. // Optica Applicata, 2008, V. XXXVIII, No.1, 65-69.

[13] Elmer T. H. Porous and Reconstructed Glasses. In: Schneider S. J. (ed.). Engineered Materials Handbook, Vol. 4: Ceramics and Glasses. Materials Park, OH: ASM International. 1991, pp. 427-432. 
[14] Novikov A.F. Characterization of the inner structure and surface of nanoporous sodiumborate-silicate glasses. // Optica Applicata, 2005. V. XXXV, No.4, pp.702-708.

[15] Basche T. [ed.], Single-Molecule Optical Detection, Imaging and Spectroscopy. VCH Publ. $1997,250 \mathrm{p}$.

[16] Gregg S., Sing C. Adsorption, Surface Area \& Porosity. L. - N.Y.: Academic Press. 1967.

[17] Lever A.B.P. Inorganic Electronic Spectroscopy. 2nd ed. Part 2, section 6.2.8. Elsevier, ser. Studies in Physical and Theoretical Chemistry 33. 1985.

[18] Rush R.M., Martin D.S., Jr., Le Grand R.G. Electronic spectra of the Pd complexes. // Inorg. Chem. 1975. V.14, № 10, pp. 2543-2550.

[19] Maitlis P. M. The Organic Chemistry of Palladium. N.Y.: Academic Press. 1971. 